\title{
THE USE OF ANTIOXIDANTS IN TREATMENT OF PATIENTS WITH GINGIVITIS \& CHRONIC PERIODONTITIS - INTERVENTION STUDY
}

\author{
Mohamed K. EL.Baz ${ }^{(1)}$; Ahmed, M. Abd El gwad ${ }^{(2)}$; \\ Hala I. Awadallah ${ }^{(2)}$ and Omaima S. EL Mahallawy ${ }^{(3)}$
}

1) Post Gard. Student, Faculty of Graduate Studies and Environmental Research, Ain Shams University 2) Faculty of Graduate Studies and Environmental Research, Ain Shams University 3) Faculty of Dentistry, Cairo University

\begin{abstract}
Background: The potential role of antioxidants in treatment of periodontitis, there is a recent interest about the relationship between antioxidants and periodontitis, so the present study was designed to prove this correlation. The aim of the present study was to investigate the effects of use of antioxidants as adjuncts in treatment of periodontitis.

Materials and Methods: This study is an original article conducted on 75 subjects from Al-Azhar University, Medical administrator department, boy's branch, from January, 2017 till August, 2019. This paper contributes to the field of topic described. The selected subjects were divided into 5 groups: clinically healthy, gingivitis treated non surgically, gingivitis treated non surgically with antioxidants supplementation, periodontitis treated non surgically, periodontitis treated non surgically with antioxidants supplementation, groups were divided according to Community Periodontal Index of Treatment Needs. At the baseline, periodontal attachment loss was recorded and scaling and root planning was performed in gingivitis and periodontitis groups. Antioxidants supplementations were administrated in the form of Selenium-ACE ${ }^{\circledR}$ single daily tablets taken orally for two weeks (Vitamin A $1500 \mathrm{IU}$ + Vitamin E $22 \mathrm{IU}$ + Vitamin C $90 \mathrm{mg}$ + Selenium 55
\end{abstract}


ug). Saliva samples were collected at baseline, $15^{\text {th }}$ day, $30^{\text {th }}$ day, and $45^{\text {th }}$ dayfor evaluation of uric acid levels.

Results: Uric acid levels were significantly low in patients with more destructive periodontitis as compared to clinically healthy and gingivitis groups. As the treatment was initiated, significant increase in uric acid levels was observed as the time elapsed.

Conclusion: the increase in salivary antioxidants levels was observed after administration of antioxidants therapy; therefore, antioxidant therapy could be used as an adjunct to nonsurgical periodontal therapy.

Keywords: Periodontitis, Antioxidants, Saliva, Uric Acid

\section{INTRODUCTION}

Chronic periodontitis is an infectious disease resulting in inflammation within the supporting structures of teeth and progressive attachment loss and bone loss (Cardoso et al., 2018). When inflamation being restricted to protective periodontium is called gingivitis and that when affecting the periodontal supporting tissues is characterized as periodontitis (Könönen et al., 2019). Periodontitis is characterized by hyper inflammation involving excess release of oxygen Free Radicals (FR) by inflammatory cells, especially Polymorphonuclear Leucocytes (PMNLs) (Silva et al., 2019). Higher concentrations of these free radicals react with certain cellular components such as DNA, proteins, lipids exerting an oxidative stress in the gingival tissues, periodontal ligament, and alveolar bone and mediate tissue damage (Kaur et al., 2016).

In normal physiology there is a dynamic equilibrium between Reactive Oxygen Species (ROS) activity and antioxidant defense capacity and when 218 Vol.(50); Iss.(8); No.(5); Aug. 2021

ISSN $1110-0826$

Online ISSN 2636-3178 
that equilibrium shifts in favor of ROS, either by a reduction in antioxidant defenses or an increase in ROS production or activity, oxidative stress results which lie at the heart of periodontal tissue damage (Trivedi \& Lal., 2017). Antioxidants remove the harmful oxidants (ROS) as soon as they form or repair the damage caused by them in vivo, A delicate balance exists between antioxidant defense and repair systems and pro-oxidant mechanism of tissue destruction which if tipped in favor of tissue damage, could lead to significant loss of attachment, this array of pathways in periodontal tissue destruction provides opportunities to develop antioxidant therapies. (Hayes et al., 2020).

Various biomarkers have been used to evaluate periodontal destruction, which include ions, enzymes, proteins, host cells, markers of cellular and humeral activity, hormones, and markers of oxidative stress and antioxidants. Uric Acid (UA) is one of the major antioxidants present in saliva and can be used to indicate the effect of antioxidant therapy in the treatment of periodontal diseases (González-Hernández et al., 2019).

When searching for adjuvants to conventional periodontal treatments that could present worse than expected results (scaling and root planning), some literature suggests that supplementation with antioxidant components may aid to reduce periodontal damage and its systemic effects if compared to treatment with antibiotics that can cause onset of secondary infections or even resistance (Javid et al., 2019). Evidence regarding the role of antioxidant agents as adjuvants to periodontal treatment is limited, that makes clinical 
Journal of Environmental Sciences (JES)

Faculty of Graduate Studies and Environmental Research, Ain Shams University

EL.Baz. et al.

decision-making difficult. Hence, this study is aimed to determine whether antioxidants have some beneficial effects on the treatment of periodontitis. 


\section{MATERIALS AND METHODS}

Seventy five subjects (42 males and 33 females) were included in this study, no subjects were lost for follow up. Number of subjects were determined on bases of flow availability in the medical department, and to facilate their division into 5 groups, 15 subjects for each. They were between 30-60 years of age. The enrolled subjects included 60 patients with moderate to advanced chronic periodontitis and 15 periodontally healthy control Subjects. Selected consecutively from those referred to the department of Medical administrator, Al- Azhar University, boy's branch; seeking for periodontal treatment.

Inclusion criteria: All selected patients were free from systemic disease, patients were selected according to Common Periodontal Index of Treatment Needs (CPITN) (Susanto et al., 2020). Exclusion criteria: 1-Patients with systemic diseases of diabetes, cardiovascular diseases, and renal Diseases. 2Subjects with a habit of smoking, pan chewing. 3-Subjects on medications of antioxidants (vitamin C, vitamin E, vitamin A or Selenium) within 3 months prior to examination. 4-Pregnant and lactating mothers.

Verbal and written approval for administration of anti-oxidant drug was obtained from patients after explaining the benefits, risks, and alternative treatments. The selected subjects were divided into five groups according to (CPITN) (Susanto et al., 2020). 
Ethical Commitment was obtained before beginning of the study, subjects were divided into;

*Group I: included 15 subjects having clinically healthy gingiva without any signs of inflammation. They were a control group that not receives any type of treatment.

*Group II: include 15 subjects suffering from gingivitis who were treated by nonsurgical periodontal therapy scaling and root planning.

*Group III: include 15 subjects suffering from gingivitis who were treated by nonsurgical periodontal therapy and were given antioxidants supplementation.

*Group IV: include 15 subjects suffering from periodontitis who were treated by nonsurgical periodontal therapy scaling and root planning.

*Group V: include 15 subjects suffering from periodontitis who were treated by nonsurgical periodontal therapy and were given antioxidants supplementation.

Antioxidant will be given in a single daily dosage of one film coated tablets taken orally every morning on an empty stomach, with Water for two weeks. Each film coated tablets is composed of (Vitamin A $1500 \mathrm{IU}+$ Vitamin E 22 $\mathrm{IU}+$ Vitamin C $90 \mathrm{mg}+$ Selenium $55 \mathrm{ug}$ ), Trade name: Selenium-ACE ${ }^{\circledR}$ tablets. 


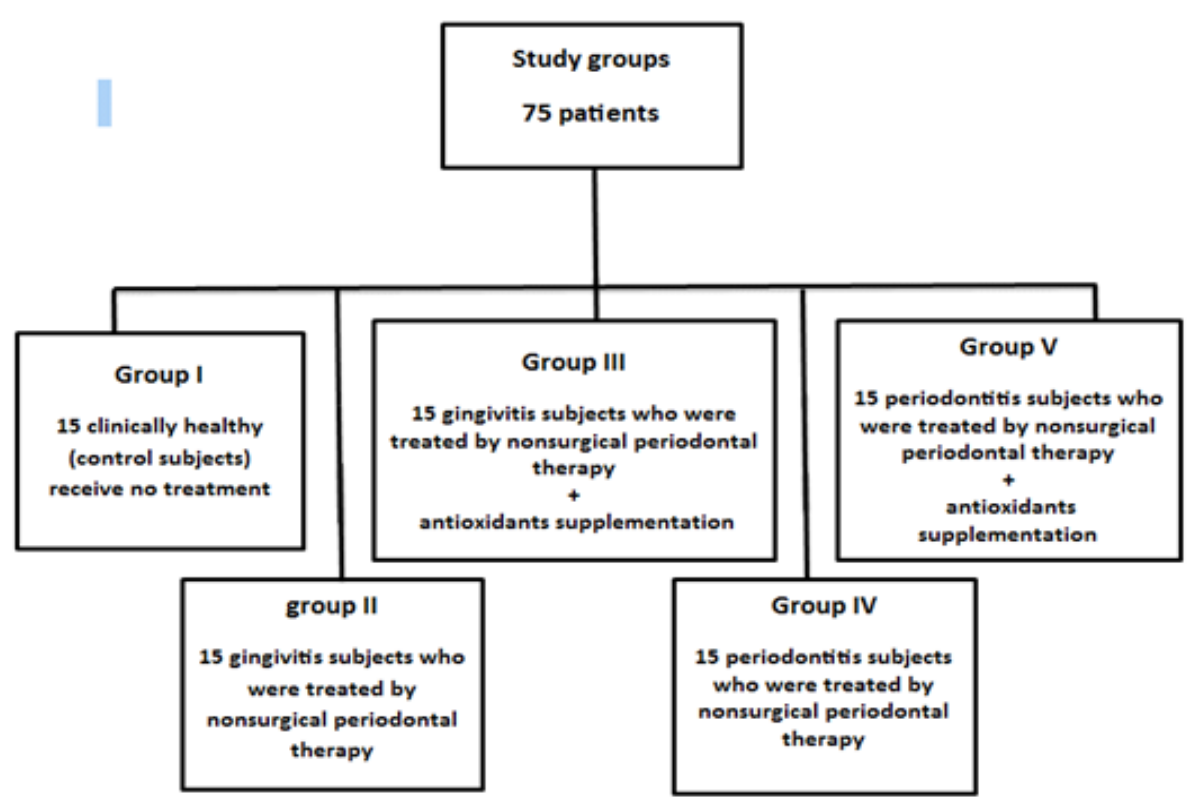

Figure1: Flowchart of the study group subjects divided according to the Community Periodontal Index of Treatment Needs (CPITN).

\section{Collection of saliva sample and uric acid determination:}

Saliva sample will be collected at baseline day, day 15 , day 30 , and day 45 for all study group members. Where $1 \mathrm{ml}$ of unstipulated saliva samples will be collected by allowing saliva to passively flow into a sterile test tube after rinsing the mouth with water to wash out the exfoliated cells. Supra gingival and sub gingival scaling were done after sample collection in Groups II, III, IV, and V. The samples of saliva from Groups II, III, IV, and V

$$
\text { Vol.(50); Iss.(8); No.(5); Aug. } 2021
$$

$$
\begin{aligned}
& \text { ISSN 1110-0826 } \\
& \text { Online ISSN 2636-3178 }
\end{aligned}
$$


Faculty of Graduate Studies and Environmental Research, Ain Shams University

EL.Baz. et al.

were collected again after 15, 30, and 45 days of nonsurgical periodontal treatment. The uric acid level was evaluated by colorimetric method. Where $20 \mathrm{UM}$ of saliva sample was taken with addition of $1 \mathrm{ml}$ of uric acid reagent and kept in incubator at $37 \mathrm{c}^{\circ}$ for $10-20 \mathrm{~min}$, then evaluation of uric acid using reflectance photometer at wavelength of $520 \mathrm{~nm}$.

\section{RESULTS}

Table (1): Descriptive statistics of periodontal index in each study groups.

\begin{tabular}{|c|c|c|c|c|c|c|c|}
\hline \multirow{3}{*}{ Groups } & \multirow{3}{*}{ Time } & \multicolumn{6}{|c|}{ Periodontal index } \\
\hline & & \multirow{2}{*}{ Min. } & \multirow{2}{*}{ Max. } & \multirow{2}{*}{ Mean \pm SD } & \multirow{2}{*}{ Median } & \multicolumn{2}{|c|}{$95 \% \mathrm{CI}$} \\
\hline & & & & & & $\mathbf{L L}$ & UL \\
\hline \multirow{4}{*}{ Group I } & Day 1 & 0.13 & 0.82 & $0.52 \pm 0.19$ & 0.50 & 0.41 & 0.62 \\
\hline & Day 15 & 0.13 & 0.82 & $0.54 \pm 0.20$ & 0.57 & 0.42 & 0.65 \\
\hline & Day 30 & 0.13 & 0.96 & $0.56 \pm 0.23$ & 0.56 & 0.43 & 0.68 \\
\hline & Day 45 & 0.10 & 0.84 & $0.54 \pm 0.22$ & 0.55 & 0.42 & 0.67 \\
\hline \multirow{4}{*}{ Group II } & Day 1 & 1.46 & 2.37 & $1.88 \pm 0.21$ & 1.84 & 1.76 & 2.0 \\
\hline & Day 15 & 1.18 & 2.06 & $1.68 \pm 0.23$ & 1.69 & 1.55 & 1.81 \\
\hline & Day 30 & 1.0 & 2.13 & $1.57 \pm 0.30$ & 1.64 & 1.41 & 1.74 \\
\hline & Day 45 & 1.07 & 2.13 & $1.65 \pm 0.25$ & 1.64 & 1.51 & 1.78 \\
\hline \multirow{4}{*}{ Group III } & Day 1 & 1.09 & 2.90 & $1.86 \pm 0.41$ & 1.80 & 1.64 & 2.09 \\
\hline & Day 15 & 0.87 & 2.37 & $1.35 \pm 0.34$ & 1.29 & 1.17 & 1.54 \\
\hline & Day 30 & 0.58 & 2.07 & $1.20 \pm 0.35$ & 1.18 & 1.01 & 1.39 \\
\hline & Day 45 & 0.45 & 1.67 & $1.21 \pm 0.33$ & 1.20 & 1.03 & 1.39 \\
\hline \multirow{4}{*}{ Group IV } & Day 1 & 3.08 & 5.60 & $4.41 \pm 0.83$ & 4.44 & 3.95 & 4.87 \\
\hline & Day 15 & 2.23 & 5.56 & $4.09 \pm 1.0$ & 4.27 & 3.54 & 4.65 \\
\hline & Day 30 & 2.83 & 5.60 & $4.20 \pm 0.87$ & 4.27 & 3.72 & 4.68 \\
\hline & Day 45 & 2.65 & 5.52 & $4.19 \pm 0.89$ & 4.33 & 3.69 & 4.68 \\
\hline \multirow{4}{*}{ Group V } & Day 1 & 3.87 & 7.0 & $5.06 \pm 0.93$ & 4.84 & 4.55 & 5.58 \\
\hline & Day 15 & 3.67 & 6.57 & $4.65 \pm 0.88$ & 4.60 & 4.17 & 5.14 \\
\hline & Day 30 & 3.78 & 6.57 & $4.59 \pm 0.87$ & 4.10 & 4.11 & 5.07 \\
\hline & Day 45 & 3.78 & 6.57 & $4.53 \pm 0.89$ & 4.05 & 4.04 & 5.02 \\
\hline
\end{tabular}


Table (2): Comparison between periodontal indexes in each group at different time interval.

\begin{tabular}{|c|c|c|c|c|c|c|}
\hline \multirow{2}{*}{ Groups } & \multicolumn{4}{|c|}{ Periodontal index } & \multirow{2}{*}{$\mathbf{F}$} & \multirow{2}{*}{$\mathbf{p}$} \\
\hline & Day 1 & Day 15 & Day 30 & Day 45 & & \\
\hline Group I & $0.52 \pm 0.19$ & $0.54 \pm 0.20$ & $0.56 \pm 0.23$ & $0.54 \pm 0.22$ & 1.734 & 0.175 \\
\hline Group II & $1.88 \pm 0.21$ & $1.68 \pm 0.23$ & $1.57 \pm 0.30$ & $1.65 \pm 0.25$ & $20.663^{*}$ & $<0.001^{\circ}$ \\
\hline $\mathbf{p}_{1}$ & & $<0.001^{*}$ & $0.001^{*}$ & $<0.001^{*}$ & & \\
\hline Group III & $1.86 \pm 0.41$ & $1.35 \pm 0.34$ & $1.20 \pm 0.35$ & $1.21 \pm 0.33$ & $44.691^{*}$ & $<0.001^{*}$ \\
\hline $\mathbf{p}_{1}$ & & $<0.001^{*}$ & $<0.001^{*}$ & $<0.001^{*}$ & & \\
\hline Group IV & $4.41 \pm 0.83$ & $4.09 \pm 1.0$ & $4.20 \pm 0.87$ & $4.19 \pm 0.89$ & 3.790 & 0.063 \\
\hline Group V & $5.06 \pm 0.93$ & $4.65 \pm 0.88$ & $4.59 \pm 0.87$ & $4.53 \pm 0.89$ & $21.477^{8}$ & $<0.001^{\circ}$ \\
\hline $\mathbf{p}_{1}$ & & $<0.001^{*}$ & $<0.001^{*}$ & $0.001^{*}$ & & \\
\hline
\end{tabular}

F: F test (ANOVA) with repeated measures, Sig. between Periods was done using Post Hoc Test (adjusted Bonferroni)

$\mathrm{p}_{1}$ : $\mathrm{p}$ value for comparing between Day1 and each other days in each group *: Statistically significant at $\mathrm{p} \leq 0.05$

Table (3): summarizes comparison between the different study groups according to periodontal index at day 45 :

\begin{tabular}{|c|c|c|c|c|c|c|c|}
\hline & $\begin{array}{l}\text { Group I } \\
(n=15)\end{array}$ & $\begin{array}{l}\text { Group II } \\
(\mathrm{n}=15)\end{array}$ & $\begin{array}{c}\text { Group III } \\
(n=15)\end{array}$ & $\begin{array}{c}\text { Group IV } \\
(n=15)\end{array}$ & $\begin{array}{l}\text { Group V } \\
(n=15)\end{array}$ & $\begin{array}{c}\text { Test of } \\
\text { Sig }\end{array}$ & $\mathbf{p}$ \\
\hline Day 45 & $4.55 \pm 20.58$ & $-12.49 \pm 8.46$ & $-33.78 \pm 18.49$ & $-5.41 \pm 4.87$ & $-10.32 \pm 7.40$ & $\mathrm{H}=35.862^{\circ}$ & $<0.001^{\circ}$ \\
\hline $\mathrm{pl}$ & & $0.001^{\circ}$ & $<0.001^{\circ}$ & 0.256 & $0.008^{\circ}$ & & \\
\hline$p_{2}$ & & & $0.023^{\circ}$ & $0.033^{\circ}$ & 0.538 & & \\
\hline Sig. bet. grps. & & & \multicolumn{3}{|c|}{$\mathrm{p}_{3}<0.001^{\circ}, \mathrm{p}_{4}=0.004^{*}, \mathrm{p}_{5}=0.129$} & & \\
\hline
\end{tabular}

F: F for ANOVA test, Pairwise comparison bet. Each 2 groups was done using Post Hoc Test (Tukey)

Vol.(50); Iss.(8); No.(5); Aug. 2021 
H: H for Kruskal Wallis test, Pairwise comparison bet. Each 2 groups was done using Post Hoc Test (Dunn's for multiple comparisons test)

$\mathrm{p}$ : $\mathrm{p}$ value for comparing between the studied groups $\mathrm{p}_{1}$ : $\mathrm{p}$ value for comparing between Group I and each other groups $\mathrm{p}_{2}$ : $\mathrm{p}$ value for comparing between Group II and Group III. $\mathrm{p}_{3}$ : $\mathrm{p}$ value for comparing between Group III and Group IV p4: $p$ value for comparing between Group III and Group V p5: $p$ value for comparing between Group IV and Group V $*$ : Statistically significant at $\mathrm{p} \leq 0.05$.

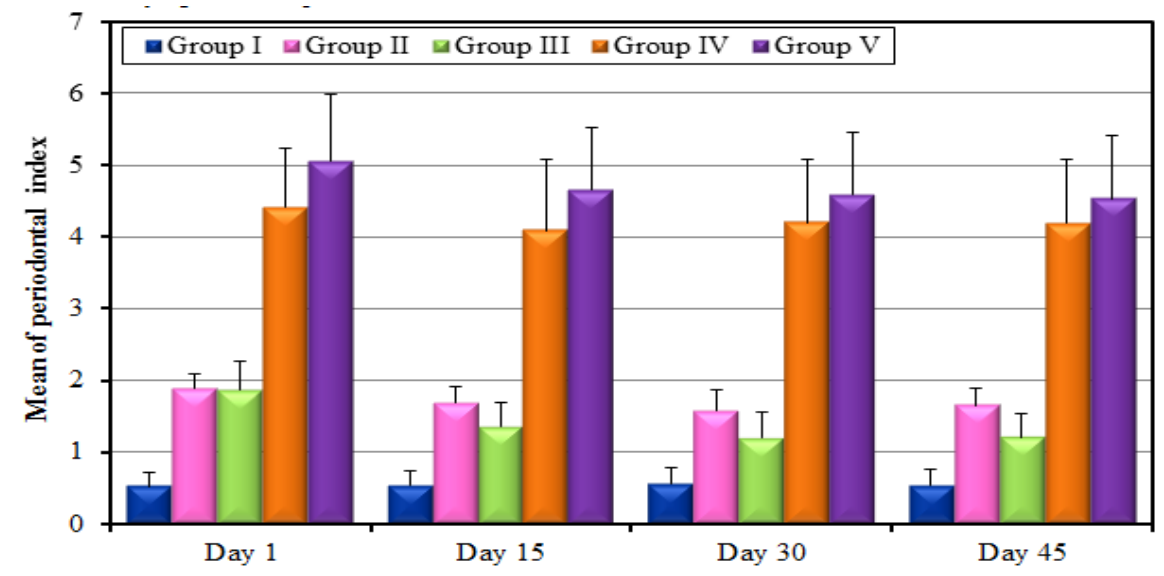

Figure (2): Comparison between the different study groups according to periodontal index. 


\section{Uric acid level:}

Table (4): Comparison between the different groups according to uric acid level at different time interval.

\begin{tabular}{|c|c|c|c|c|c|c|}
\hline \multirow{2}{*}{ Group } & \multicolumn{4}{|c|}{ Uric acid level } & \multirow{2}{*}{$\mathbf{F}$} & \multirow{2}{*}{$\mathbf{p}$} \\
\hline & Day 1 & Day 15 & Day 30 & Day 45 & & \\
\hline Group I & $5.09=0.50$ & $5.15 \pm 0.45$ & $5.20=0.50$ & $5.19 \pm 0.58$ & 0.795 & 0.466 \\
\hline Group II & $3.23 \pm 0.23$ & $3.41 \pm 0.23$ & $3.66 \pm 0.18$ & $3.82 \pm 0.23$ & $72.923^{*}$ & $<0.001=$ \\
\hline p1 & & $0.004^{*}$ & $<0.001 *$ & $<0.001 *$ & & \\
\hline Group III & $2.44 \pm 0.52$ & $2.92 \pm 0.50$ & $3.43 \pm 0.47$ & $3.83=0.50$ & $111.205^{*}$ & $<0.001^{*}$ \\
\hline p1 & & $<0.001^{*}$ & $<0.001 *$ & $<0.001 *$ & & \\
\hline Group IV & $2.50=0.15$ & $2.94 \pm 0.23$ & $3.23 \pm 0.29$ & $3.54 \pm 0.34$ & $48.902^{*}$ & $<0.001 *$ \\
\hline p1 & & $<0.001=$ & $<0.001=$ & $<0.001 *$ & & \\
\hline Group V & $2.46 \pm 0.30$ & $2.94 \pm 0.41$ & $3.27 \pm 0.32$ & $3.69 \pm 0.35$ & $62.465^{*}$ & $<0.001 *$ \\
\hline $\mathbf{p}_{1}$ & & $0.002^{*}$ & $<0.001=$ & $<0.001=$ & & \\
\hline
\end{tabular}

F: F test (ANOVA) with repeated measures, Sig. between periods was done using Post Hoc Test (adjusted Bonferroni).

$\mathrm{p}_{1}$ : p value for comparing between Day1 and each other days in each group

$*$ : Statistically significant at $\mathrm{p} \leq 0.05$

\section{DISCUSSION}

Periodontitis is a chronic inflammatory manifestation in the surrounding tissues of the teeth caused by an imbalance between the host's response and oral biofilms, in which there is a possibility of loss of support tissues of the tooth (Cardoso et al., 2018). The state when being restricted to protective periodontium is called gingivitis, and that when affecting the periodontal supporting tissues is characterised as periodontitis; However, periodontitis appears to result in a chronic progression, mostly, it is characterized by active 
Journal of Environmental Sciences (JES)

Faculty of Graduate Studies and Environmental Research, Ain Shams University

EL.Baz. et al.

stages with the attachment loss and stages of disease stagnation as it results from an interplay between chronic bacterial infection and the local and systemic inflammatory host response (Könönen et al., 2019). Periodontitis is one of the most oral cavity prevalent diseases, caused by bacterial plaque microorganisms and influenced by factors such as age, systemic condition, sex, oral hygiene, and smoking (Nazir., 2017).

This study demonestrated that the antioxidant effects of selenium on periodontal health as it reduces oxidative stress, improves the antioxidant status, and decreases markers of inflammation). and this agree with Gorshkova et al., (2019), vit A (Naruishi., 2021).

In this study by using antioxidants as an adjunctive to non-surgical scaling and root planning, The results show that periodontal index reduced significantly in all groups before and after Scaling and Root Planning (SRP); this reduction in the intervention group was higher than the control group. These results agree with (Elgendy et al.,2013) who used a different type of antioxidants (oil gel) on long pentraxin level used as an adjunctive treatment of chronic periodontitis in a randomized controlled clinical study and who conclude that both periodontal index and pocket depth were reduced significantly in both groups before and after (SRP) ; this reduction in the intervention group was higher than the control group. .

The same results were obtained by Hrishi et al., (2016) who concluded that all parameters showed a significant improvement in the comparison of 
the test group with the control group after application of scaling and root planning In addition to application of chlorhexidine $0.06 \%$ antioxidants.

The same results obtained by Kharaeva et al., (2016) who used coenzyme Q10 oral supplements as an adjunct antioxidant to (SRP) and showed significant reduction in gingival inflammation when compared to scaling and root planning alone.

Chopra et al., (2016) On the other hand observed that local delivery of antioxidant Gel formulation was prepared from Tea Tree Oil (TTO) (5\%) in case of chronic periodontitis may have some beneficial effects but not significant, this is may be due to using local delivery system not systemic.

This run in the same way with Alkadasi et al., (2017) who found no statistically significant differences in gingival crevicular fluids levels were observed in the sites that underwent surgical treatment with or without $\mathrm{N}$ Acetylcysteine (NAC) capsules at different time intervals, the difference in results between the two studies may be due to using small sample of 20 subjects so further longitudinal studies with larger sample size coupled with other inflammatory markers are required.

In the present study, we found a direct positive correlation between periodontal health and adjunctive antioxidant supplementation with nonsurgical therapy (SRP). Improvement in clinical parameters was found to be statistically significant in both groups following therapy compared to baseline. Although SRP is a standard means of controlling inflammation (Al- 
Journal of Environmental Sciences (JES)

Faculty of Graduate Studies and Environmental Research, Ain Shams University

EL.Baz. et al.

Hamoudi et al., 2020) the improvement in test group receiving antioxidant therapy were statistically significant $(\mathrm{P}=0.001)$ and greater as compared to the control group, These results in agreement with Tripathi et al., (2019) who used lycopene with green tea extract and proved to have adjunctive prophylactic and therapeutic modality in the treatment of gingivitis patients.

This results are in accordance with other studies which have reported inverse association between periodontal disease and antioxidant Chandra et al., (2013) who concluded that locally delivered lycopene seems to be effective in reducing the measures of oxidative stress and periodontal disease.

This study agree with other study conducted by Sharma et al., (2017) who found that antioxidant has major role in the treatment of the inflammation of periodontal tissue and can enhance the time of treatment and this agree with this study.

In this study, significant difference was observed in the periodontal index values between healthy, gingivitis, and periodontitis group on baseline and $45^{\text {th }}$ day. Similar results were also observed in a study by Jahanghirnejad et al., (2018).

Uric acid (UA) plays a major role as an antioxidant present in the whole saliva (González-Hernández et al., 2019), UA levels have been reported to be directly correlated with local and systemic Total Antioxidants Capacity (TAC) levels (Feriani et al., 2021). In the present study there was a statistically significant difference in mean Uric acid levels at baseline in the five groups. Healthy group showed a higher mean Uric acid level, A marked 230 
decrease in the salivary uric acid levels were observed in the gingivitis and periodontitis groups in comparison to healthy one, these results agree with other study conducted by Tripathi, et al., (2019), and (Wasti et al., 2021).

On the contrary, some authors demonstrated that UA levels in periodontitis patients have been found to be higher than in gingivitis patients (Talmaç \& Çalişir., 2019), this is may be due to the use of different antioxidants with different doses.

In the present study we found that there was a significant increase in uric acid levels in all groups before and after (SRP); of both gingivitis and periodontitis groups, Although no significant difference could be observed in uric acid levels between scaling and root planning, and scaling and root planning with antioxidant, an increase in the mean uric acid levels was observed as the time elapsed. This indicates that there is some role of antioxidants in periodontal health.

similar results were obtained by Mazur et al., (2021) in his study who observed that though there was no significant difference in uric acid levels in between groups treated with a combination of oral prophylaxis and antioxidant and group treated with (SRP) alone, there was a better response to antioxidant therapy in combination to oral prophylaxis in the gingivitis and periodontitis groups.

The same results were obtained by Tripathi et al., (2019) who found that supplementation with antioxidants resulted in an increase in mean salivary 
UA levels. In a recent systemic review, Zhang et al., (2017) concluded that drinking green tea may be positively associated with the serum UA level.

On the contrary, some authors demonstrated that green tea extract may modestly lower salivary UA level and decreases uric acid clearance. (Jatuworapruk et al., 2014) however, current literature does not provide enough evidence establishing this hypothesis, hence further investigation are needed regarded this issue.

\section{CONCLUSION}

Rise in salivary antioxidant (UA) levels was observed upon the administration of antioxidant therapy (Selenium, Vit A, C, and E). Hence, antioxidant therapy can be used as an adjunct to the nonsurgical periodontal therapy.

\section{RECOMMENDATIONS}

1- Further longitudinal studies with larger sample size coupled with other inflammatory markers are required to establish the role of antioxidant therapy in periodontal diseases.

2- Focus should be laid on research and nutritional supplementation of exogenous antioxidants in the management of gingivitis and periodontitis.

3- More than one type of antioxidants can be used.

\section{REFERENCES}


Al-Hamoudi, N., Alsahhaf, A., Al Deeb, M., Alrabiah, M., Vohra, F. and Abduljabbar, T., 2020. Effect of scaling and root planing on the expression of anti-inflammatory cytokines (IL-4, IL-9, IL-10, and IL-13) in the gingival crevicular fluid of electronic cigarette users and non-smokers with moderate chronic periodontitis. Journal of periodontal \& implant science, 50(2):74.

Alkadasi, B., Abdulrab, S., Gaafer, S., Kalakonda, B., Hosny, M., Shaker, O. and Hosny, M., 2017. Effect of adjunctive use of systemic antioxidant therapy ( $\mathrm{N}$-acetylcysteine) on soluble receptor activator nuclear factor $\kappa \mathrm{B}$ ligand levels in gingival crevicular fluid following surgical periodontal treatment for chronic periodontitis. Journal of oral science:16-0701.

Cardoso, E.M., Reis, C. and Manzanares-Céspedes, M.C., 2018. Chronic periodontitis, inflammatory cytokines, and interrelationship with other chronic diseases. Postgraduate medicine, 130(1):98-104.

Chandra, R.V., Srinivas, G., Reddy, A.A., Reddy, B.H., Reddy, C., Nagarajan, S. and Naveen, A., 2013. Locally delivered antioxidant gel as an adjunct to nonsurgical therapy improves measures of oxidative stress and periodontal disease. Journal of periodontal \& implant science, 43(3):121.

Chopra, A., Thomas, B.S., Sivaraman, K., Prasad, H.K. and Kamath, S.U., 2016. Green Tea Intake as an Adjunct to Mechanical Periodontal Therapy for the Management of Mild to Moderate Chronic Periodontitis: A Randomized Controlled Clinical Trial. Oral health \& preventive dentistry, 14(4).

Elgendy, E.A., Ali, S.A.M. and Zineldeen, D.H., 2013. Effect of local application of tea tree (Melaleuca alternifolia) oil gel on long pentraxin level used as an adjunctive treatment of chronic periodontitis: A randomized controlled clinical study. Journal of Indian Society of Periodontology, 17(4):444. 
Feriani, D.J., Sousa, A.S., Delbin, M.A., Ruberti, O.M., Crestani, C.C. and Rodrigues, B., 2021. Spleen tissue changes after restraint stress: effects of aerobic exercise training. Stress:1-12.

González-Hernández, J.M., Franco, L., Colomer-Poveda, D., MartinezSubiela, S., Cugat, R., Cerón, J.J., Márquez, G., Martínez-Aranda, L.M., Jimenez-Reyes, P. and Tvarijonaviciute, A., 2019. Influence of sampling conditions, salivary flow, and total protein content in uric acid measurements in saliva. Antioxidants, 8(9):389.

Gorshkova, A.E., 2019. The results of the use of selenium in the complex treatment of patients with chronic generalized periodontitis. Ukrainian Dental Almanac, (4):5-10.

Hayes, J.D., Dinkova-Kostova, A.T. and Tew, K.D., 2020. Oxidative stress in cancer. Cancer Cell.

Hrishi, T.S., Kundapur, P.P., Naha, A., Thomas, B.S., Kamath, S. and Bhat, G.S., 2016. Effect of adjunctive use of green tea dentifrice in periodontitis patients-A Randomized Controlled Pilot Study. International journal of dental hygiene, 14(3):178-183.

Isola, G., Polizzi, A., Muraglie, S., Leonardi, R. and Lo Giudice, A., 2019. Assessment of vitamin $\mathrm{C}$ and antioxidant profiles in saliva and serum in patients with periodontitis and ischemic heart disease. Nutrients, 11(12):2956.

Jahanghirnejad, M., Babadi, F., Safikhani, E., Hemmati, A.A. and Amiri, Y., 2018. Comparison of the effects of chlorhexidine mouthwash with jaftex on periodontal index. Jentashapir Journal of Health Research, 9(1).

Jatuworapruk, k., Srichairatanakool, S., kasitanon, N., Wangaew, S., \&Louthrenoo, W. (2014). Ffcts of grn ta xtract on srum uri ai an urat claran inhalthy iniviuals. JCR: Journal of lineal rhmatology, 20(6), 310. 
Javid, A.Z., Bazyar, H., Gholinezhad, H., Rahimlou, M., Rashidi, H., Salehi, P. and Haghighi-Zadeh, M.H., 2019. The effects of ginger supplementation on inflammatory, antioxidant, and periodontal parameters in type 2 diabetes mellitus patients with chronic periodontitis under non-surgical periodontal therapy. A doubleblind, placebo-controlled trial. Diabetes, metabolic syndrome and obesity: targets and therapy, 12:1751.

Kaur, G., Kathariya, R., Bansal, S., Singh, A. and Shahakar, D., 2016. Dietary antioxidants and their indispensable role in periodontal health. Journal of food and drug analysis, 24(2):239-246.

Kharaeva, Z.F., Zhanimova, L.R., Mustafaev, M.S., De Luca, C., Mayer, W., Chung Sheun Thai, J., Tiew Siok Tuan, R. and Korkina, L.G., 2016. Effects of standardised fermented papaya gel on clinical symptoms, inflammatory cytokines, and nitric oxide metabolites in patients with chronic periodontitis: an open randomised clinical study. Mediators of inflammation, 2016.

Könönen, E., Gursoy, M., \& Gursoy, U. K. (2019). Periodontitis: A multifaceted disease of tooth-supporting tissues. Journal of clinical medicine, 8(8), 1135 ..

Mazur, M., Ndokaj, A., Jedlinski, M., Ardan, R., Bietolini, S. and Ottolenghi, L., 2021. Impact of Green Tea (Camellia Sinensis) on periodontitis and caries. Systematic review and meta-analysis. Japanese Dental Science Review, 57:1-11.

Naruishi, K. (2020). Carotenoids and periodontal infection. Nutrients, 12(1), 269.

Nazir, M. A. (2017). Prevalence of periodontal disease, its association with systemic diseases and prevention. International journal of health sciences, 11(2), 72 .

Sharma, S., Bhuyan, L., Ramachandra, S., Sharma, S., Dash, K.C. and Dhull, K.S., 2017. Effects of green tea on periodontal health: A 
prospective clinical study. Journal of International Oral Health, 9(2):39.

Susanto, A., Carolina, D. N., Amaliya, A., Pribadi, I. M. S., \& Miranda, A. (2020). Periodontal health status and treatment needs of the community in Indonesia: A cross sectional study. Journal of International Oral Health, 12(2), 114.

Talmaç, A.C. and Çalişir, M., 2019. Antioxidants and Periodontal Diseases. In Gingival Disease-A Professional Approach for Treatment and Prevention. IntechOpen.

Tripathi, P., Blaggana, V., Upadhyay, P., Jindal, M., Gupta, S., \& Nishat, S. (2019). Antioxidant therapy (lycopene and green tea extract) in periodontal disease: A promising paradigm. Journal of Indian Society of Periodontology, 23(1), 25.

Trivedi, S. and Lal, N., 2017. Antioxidant enzymes in periodontitis. Journal of oral biology and craniofacial research, 7(1):54-57.

Wasti, J., Wasti, A., \& Singh, R. (2021). Efficacy of antioxidants therapy on progression of periodontal disease-A randomized control trial. Indian J of Dental Research 31(2):252-256.

Zhang, Y., Cui, Y., Li, X. A., Li, L. J., Xie, X., Huang, Y. Z., \& Lei, G. H. (2017). Is tea consumption associated with the serum uric acid level, hyperuricemia or the risk of gout? A systematic review and meta-analysis. BMC musculoskeletal disorders, 18(1): 1-10. 


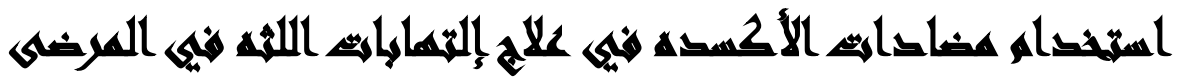

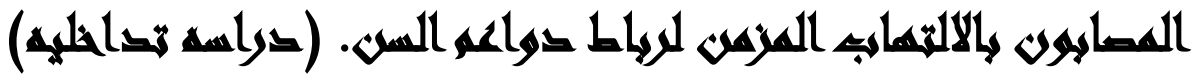

محمد كامل الاسوقي الباز (')- أحمد ممدوح عبد الجواد(؟)- هاله (براهيم عوض الله (ץ) إ)

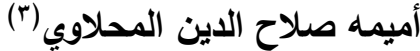

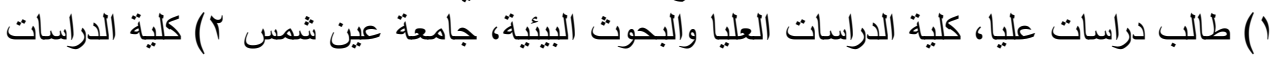
العليا والبحوث البيئية، جامعة عين شمس بل كلية كلية طب الأسنان، جامعة القاهرة

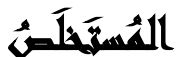

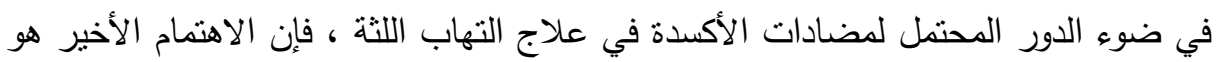

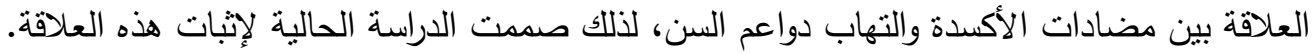

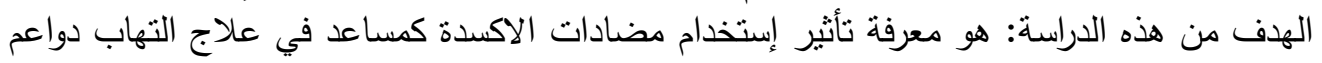

المواد والطرق المستخدمه: تم تقسيم V0 شخصا الي خمس مجموعات( صحي إكلينيكيا، حالات

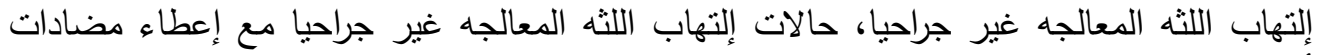

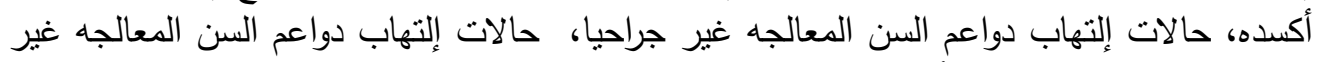

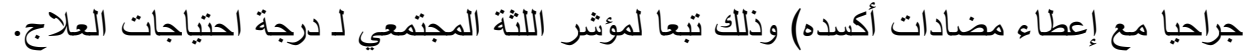

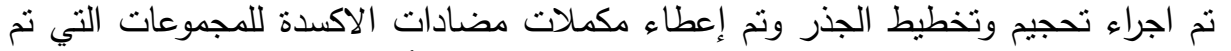

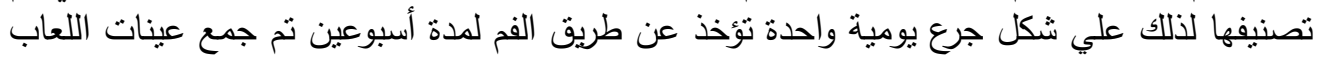

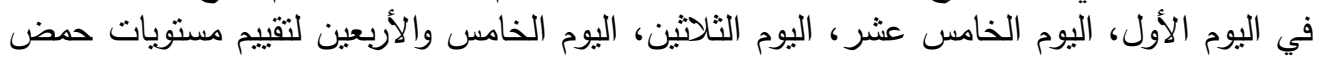
اليوريك.

النتائج: كانت مستويات حمض اليوريك منخفضة بشكل ملحوظ في المرضي الذين يعانون من التهاب

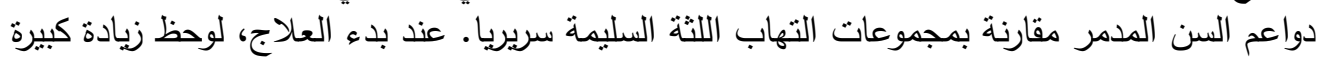
في مستويات حمض اليوريك مع مرور الوقت.

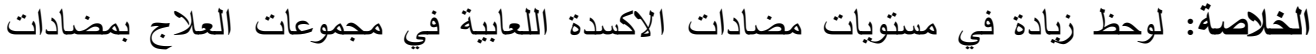

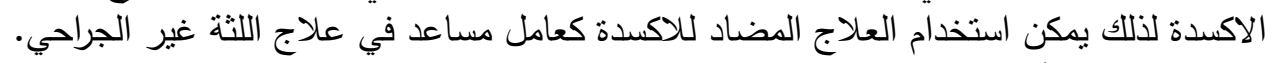

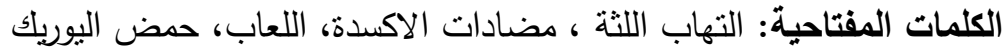

Vol.(50); Iss.(8); No.(5); Aug. 2021 